\title{
DESEMPREGO: a instituição política de uma questão social*
}

\author{
Vivian Molina Noccioli
}

\author{
Especialista em Sociologia e Sociologia da Educação.
}

O presente artigo apresenta uma discussão sobre a questão do desemprego como decorrente da relação entre capital e trabalho, apontando o fator desigualdade não apenas como exclusão do trabalho e do processo capitalista mas em relação à violação do direito ao trabalho.

Palavras-chave: trabalho; desigualdade; exclusão; direito; cidadania.

\section{DESEMPREGO: DESIGUALDADE E EXCLUSÃO}

A $s$ dicotomias trabalho/não-trabalho, emprego/desemprego são discutidas pela teoria marxista como decorrências de crises conjunturais do sistema capitalista ocasionadas pela desigualdade inerente à relação entre capital e trabalho. Segundo a tradição marxista, os meios de produção são propriedade do capitalista, sendo os trabalhadores excluídos de qualquer possibilidade de discussão sobre a destinação, organização e planejamento do trabalho.

O controle capitalista do processo de trabalho é autoritário e sustentado por uma hierarquia de gerentes sob comando do capitalista. É a desigualdade inerente à relação entre capital e trabalho que também determina a estrutura de classes na formação social capitalista. (LANG, 1982)

Na década de 80 , países de capitalismo avançado vivenciaram uma crise aguda do trabalho, que trouxe transformações para o processo de trabalho, de produção de capital e de mercadorias. Foi esse o tempo do salto tecnológico que revolucionou a técnica no interior do capitalismo, principalmente no que diz respeito às forças produtivas. Nesse momento o movimento operário encontra-se em crise, pois sua forma de ser enquanto classe foi também transformada, afetando organismos que a representavam, como sindicatos e partidos de esquerda que mantinham vínculos com a classe trabalhadora.
"É então um processo de organização do trabalho fundado numa resposta imediata à demanda, numa organização flexível do trabalho, numa produção integrada que em certo sentido leva o estranhamento do trabalhador ao limite, fazendo com que as respostas do mundo do trabalho encontrem-se em algumas situações num quadro muito defensivo". (ANTUNES, 1996, p.9-10)

Nessa perspectiva, o assalariado permanece, ao longo dos tempos, às margens da sociedade instalando-se, como subordinado. Tais discussões atribuem posição, situam e classificam o indivíduo na sociedade de forma intrínseca ao trabalho, em detrimento de outras configurações de identidade do indivíduo, como o pertencimento familiar ou o seu relacionamento em determinada comunidade concreta.

A nova ordem mundial reflete o perfil de trabalhadores sem trabalho, como observa Hannah Arendt. "São trabalhadores que ocupam na sociedade um lugar de supranumerários, de inúteis para o mundo". (cf. CASTEL, 1998, p.496)

Porém, mesmo diante dessa situação não podemos afirmar que se trata apenas do fim do emprego, mas sim da transformação do papel integrador do trabalho. Cabe, então, a pergunta: seria o trabalho, ainda, uma questão central para as ciências sociais?

O fato de afirmarmos que uma pessoa trabalha, i.é, que tem um emprego formal, assume menor relevância para o conteúdo social no tocante aos interesses individuais e até mesmo aos estilos de vida. Assim, podemos fazer uma diferenciação interna do conceito tradicional de divisão do tra-

\footnotetext{
* O texto é uma adaptação da monografia de mesmo nome apresentada como trabalho de conclusão do curso de Especialização em Sociologia e Sociologia da Educação, da UEL, em março de 1999, sob orientação da professora Ana Cleide Chiarotti Cesário.
}

Rev. Mediações, Londrina, v. 4, n. 2, p. 58-65, jul./dez. 1999 
balho, visto que o conceito tradicional não contempla a discussão atual, uma vez que, hoje, existem os que terceirizam o seu trabalho e os que se vinculam a atividades informais coexistindo com a forma tradicional de divisão do trabalho.

\begin{abstract}
"A diferenciação interna contínua da coletividade dos trabalhadores assalariados, assim como a erosão dos alicerces culturais e políticos de uma identidade coletiva centrada no trabalho, ampliam estes dilemas das formas de trabalho assalariado contemporâneas a ponto de o fato social do trabalho assalariado ou da dependência com relação ao salário não serem mais o foco de intenção coletiva e de divisão social e política." (OFFE, 1989, p.177)
\end{abstract}

Assim, ao final deste milênio, com a globalização e a terceirização, o não-trabalho - ou desemprego —, além de expressar desigualdade, pode expressar, também, exclusão. Isso talvez signifique desfocar a análise do trabalho para outras instâncias da sociedade (formas de sociabilidade fora do trabalho), como o mundo privado e o mundo público restrito, bairros e vizinhança.

Sabemos que as categorias trabalho, emprego, divisão social do trabalho nuclearam grande parte da teoria social da modernidade aos nossos dias. Atualmente, somos tentados a aventar a possibilidade de que a análise social e política - pode se deslocar para formas de sociabilidade que se encontram fora do mundo do trabalho, i. é., no mundo privado e nas redes de relações sociais próximas ao indivíduo, nas quais questões como etnia, gênero e idade, acompanhadas pela desigualdade e também pela exclusão, estão latentes. Todavia, suas formas de manifestação, segundo KOWARICK (1997), tendem a se apresentar mais como forma de sociabilidade primária no mundo privado do que, propriamente, no mundo público, aquilo a que o autor denomina "cidadãos privados". "Daí a noção de cidadania privada: Privada na acepção de não ter acesso a benefícios e na de estar separado, isolado, excluído". (KOWARICK, 1997, p.4)

Diante destas questões, minha reflexão focalizará o desemprego nesse território limítrofe da vida privada e da possibilidade de instituição do desemprego no espaço público tendo em vista a perspectiva da dinâmica dos direitos.

\section{ESPAÇO PÚBLICO: O LUGAR DA CIDADANIA}

Hannah Arendt, ao discutir os espaços público e privado na Grécia antiga, identifica o mundo privado como o lugar do trabalho, enquanto o espaço público (da política) é reservado ao cidadão, i. é., àquele que se "libertou" do trabalho, podendo se dedicar à política já que contava com escravos e mulheres para executar o trabalho no oikos. De acordo com a autora, é na modernidade que emerge o social afigurando-se como o lugar do trabalho, restringindo gradativamente o espaço privado ao lugar da intimidade e conferindo ao Estado o papel de gestor do social. Como decorrência, a política perde o seu estatuto próprio e, aos poucos, o espaço público perde densidade. Desse modo, Arendt defende a politização do espaço público a partir da consciência do direito a ter direitos. (ARENDT, 1992)

Por seu lado, LEFORT (1987) enfatiza que, na modernidade, a democracia tem seu embrião no sufrágio universal, que desintrinca as esferas do poder, da lei e do saber. Este é o momento da transformação do corpo (o político) em carne (o social) e que, portanto, demanda a procura do político nos lugares e momentos em que ele não aparece. Segundo o autor, o mito fundador da democracia e dos direitos é a Carta dos Direitos Humanos nas sociedades ocidentais, porém é importante repensá-los e dinamizá-los socialmente.

"Nada se pode dizer de rigoroso sobre uma política dos direitos do homem enquanto não se examinar se esses direitos tem uma significação propriamente política, e nada se pode avançar sobre a natureza do político que não ponha em jogo uma idéia da existência ou, o que dá no mesmo, da coexistência humana." (LEFORT, 1987, p.38)

Diante das transformações estruturais da nova ordem mundial, e a não-garantia dos direitos dos cidadãos, podemos ter como referência o que promulga a Declaração dos Direitos do Homem e do Cidadão. Este documento, publicado pelos franceses reunidos em assembléia nacional em 1789 , visava definir princípios válidos para todos os homens.

"A garantia dos direitos do homem e do cidadão necessita de uma força pública; essa força é assim instituída para o benefício de todos e não para a utilidade particular daqueles a quem é confiada." (Declaração dos Direitos do Homem e do Cidadão - Artigo XII apud FALCON \& MOURA, 1989, p.69-70)

Podemos perceber que estes direitos, considerados por LEFORT (1991) como o mito fundador das sociedades ocidentais, não estão sendo assegurados. Dessa forma, é preciso repensar se tais direitos têm, realmente, significado político.

Contudo, é importante perceber que esta proposta requer a discussão dos direitos como conquistas a partir da constituição e legitimação do espaço público e a afirmação do significado da palavra direito, o que podemos perceber na discussão de DAGNINO (1994). Segundo a autora, existem três dimensões para a emergência de uma nova noção de cidadania: a primeira, ligada à experiência concreta de movimentos sociais em sua luta por direitos seja na igualdade seja na diferença; a segunda, ligada à ênfase de construção da democracia, expressando um novo estatuto teórico e político e assumindo a participação; a terceira, fundamental para a emergência de uma nova noção de cidadania, ligada à organização estratégica da construção democrática da transformação social, ou seja, à construção da cidadania a partir da difusão de uma cultura democrática.

Como bem salienta a autora, a elaboração de uma cultura democrática é crucial para o Brasil e também para a América Latina, tendo em vista seus problemas em comum. Por exemplo, o desemprego, ou o ordenamento social de uma organização hierárquica e desigual, a que Dagnino denomina 
autoritarismo social, que coloca pessoas diferentes nos seus respectivos lugares, sendo este o princípio da exclusão.

KOWARICK (1997), ao abordar esta questão, faz uma discussão sobre público e privado adotando a noção de cidadão privado. Diante da criminalidade, mas também em face da violência que se expressa na miserabilidade, moradia em favelas e cortiços, na precariedade do transporte coletivo, entre outras tarefas públicas não cumpridas, o cidadão brasileiro recolhe-se em sua vida privada, o meio no qual existe solidariedade estruturada em torno da casa e da vizinhança. Privatiza sua vida pública através da cidadania privada, na medida em que não tem acesso a benefícios, ou seja, por estar excluído do espaço público. Lúcio Kowarick aponta três aspectos importantes que contribuem para o processo de exclusão social: a questão econômica, o Estado e a negação dos direitos civis.

O problema econômico torna-se mais acirrado na década de 80 , "a década perdida", momento em que a crise é generalizada, sem crescimento econômico e sem distribuição de renda. O pauperismo aumenta multiplicando-se as modalidades de trabalho assalariado precário e mão-de-obra irregular. O Estado perde o controle sobre as políticas públicas, a insignificância de pensões e aposentadorias dão margem à pauperização de pessoas idosas que dependem desta renda.

Podemos perceber que, para o autor, a ausência de direitos civis se faz nos aspectos mais elementares, pobreza, moradia e grupos de idosos. Existem famílias que, a depender de suas composições, encontram-se em condições de miserabilidade ou pobreza, pois a vulnerabilidade familiar decorre de várias formas de inserção no mercado de trabalho, bem como em situações de desemprego.

Esta perspectiva propicia perceber que a moradia está relacionada aos direitos sociais e à cidadania, pois o espaço em que famílias se encontram no tecido urbano evidencia a segregação social. Desse modo, o autor relaciona o aspecto moradia com o grupo dos idosos, por não existir políticas que discriminem positivamente este grupo, tais como melhores aposentadorias, assistências à saúde e moradia. A idade engendra desvalorização e o velho é diminuído não apenas pelo empobrecimento mas também pelo isolamento.

Pela primeira vez na teoria social, as dimensões igualdade, liberdade e cidadania são reconhecidas como princípios de emancipação da vida social. Nesse sentido, é preciso encarar a exclusão e a desigualdade como dimensões que se complementam para o entendimento do processo social. SANTOS (1995) discute a problemática da desigualdade e da exclusão, salientando que tanto a desigualdade quanto a exclusão são sistemas de pertença hierarquizados. Na desigualdade, o sistema se mantém pela integração subordinada, ou seja, o desigual é incluído e rebaixado devido à hierarquia existente em diversas modalidades de trabalho. Tal fato se torna mais claro quando pensamos a relação entre capital e trabalho, segundo a formulação de Karl Marx, bem como seu entendimento sobre a desigualdade classista baseada na exploração.

A questão da exclusão também perpassa a hierarquia, exclui-se quem está abaixo e já não tem mais utilidade alguma ou não se encontra à disposição para qualquer função. $\mathrm{O}$ princípio da exclusão é simplesmente excluir, e sua forma mais extrema é o extermínio físico. (SANTOS, 1995)

Porém, a desigualdade e a exclusão são construídas socialmente. O excluído, seja por sexo, raça ou "anormalidade" perante os padrões instituídos, tem seus espaços público e privado totalmente desconstruídos.

Contudo, a modernidade capitalista mantém limites de exclusão e desigualdade através de mecanismos de regulação social. $\mathrm{O}$ universalismo é um destes mecanismos e pode ser aplicado como diferencista ou anti-diferencista.

O universalismo diferencista opera pela negação da hierarquia, seguindo a norma da homogeneização criando um excesso de semelhanças, o que desconsidera sumariamente os critérios transculturais.

O modelo anti-diferencista descaracteriza a diferença e reproduz a hierarquização. É este mecanismo que confronta a desigualdade através de políticas do Estado-Providência, mantendo a desigualdade até o limite em que não inviabilize a integração subordinada.

Este modelo, segundo SANTOS (1995), é regulador, uma vez que produz desigualdade mas a mantém em seus limites funcionais. Movimentos organizados em nível nacional - embora o capitalismo seja mundial - têm o Estado como controlador em supremacia. Sendo assim, qualquer luta ou conquista de cidadania será institucionalizada.

É possível, então, concordar com LEFORT (1991) quando, em seu diálogo com Hannah Arendt, afirma que é preciso repensar o político.

A democracia funda uma história de homens indeterminados quanto ao fundamento da lei, do poder e do saber; para Lefort, quando o direito está em suspenso, o poder na dependência do conflito e as conquistas são ilegítimas, a lógica democrática está em aberto, dando lugar a regimes autoritários.

Enquanto para ARENDT (1992) a democracia é um espaço a ser construído, para LEFORT (1991) é o território das incertezas. Assim, o paradoxo da democracia é não poder entender a soberania popular relacionada apenas ao número de manifestantes. $O$ autor destaca que relações sociais, solidariedade e redes de vida social são fatores importantes na construção da democracia. Para Lefort, a importância está também na transformação do Estado, propondo três modelos de Estado que predominam ao longo da história: o liberal, o totalitário e o Providência.

O primeiro, a priori, é o guardião dos direitos civis, mas, na prática, tornou-se guardião dos interesses da classe dominante, e somente a luta constante das massas poderia abalá-lo. Este modelo corre o risco de ser uma abstração se extraído da configuração de sociedade democrática, pois em uma sociedade investida da autoridade a opinião é unanimidade, a lei uniformidade e o poder do Estado é a regulamentação.

No segundo, o regime totalitário, existe uma mudança de estatuto de poder, pois o partido totalitário torna-se uma oposição entre outros partidos, dando idéia de renovação. Para ARENDT (1992), o totalitarismo mantém desprezo por leis positivas, mas agencia-se sobre o uso das leis. Esta é a diferença básica entre totalitarismo e democracia. Nesta última é abolido o lugar onde a lei é transcendente, 
não confundida com o poder. O totalitarismo combina um ideal artificialista com um ideal radicalmente organicista, organizando a "democracia" em um sistema de instituições.

É esta quebra de tempo orgânico que delineia o homem, tornando-o sem história. Na democracia a sociedade é histórica e preserva a indeterminação do homem contra o totalitarismo.

O terceiro, o Estado-Providência, segundo Lefort (1991), neutraliza a expressão dos conflitos sociais, garante o bem-estar social e não é guardião por não ter um senhor. Surge o poder impessoal, que se afirma como onipresente e reforça seu domínio sobre os homens, pois parece ser democrático quando, na verdade, se apresenta como de ninguém.

Não é o Estado que deve garantir o direito à resistência e sim o cidadão; a opressão deve significar ameaça à nação e o bem-estar não é tudo que uma sociedade precisa.

Ainda segundo Lefort, a relação entre Estado e indivíduo deve se estabelecer a partir do desenvolvimento da democracia e do reconhecimento do espaço público. A vontade geral é reconhecida na lei e a sua elaboração implica participação dos cidadãos. Os direitos do homem desintrincam direito e poder, pois, para que seja legítimo, o poder tem que ser igual ao direito.

A liberdade tem que ser tudo o que não prejudique 0 outro: traz o indivíduo às suas esferas de atividade, fazendoo movimentar-se por onde bem quiser e exercendo a liberdade de opinião e de relações sociais e políticas.

Assim, o Estado continua acima das opiniões, mas as transformações advêm do reconhecimento do espaço público, e a resistência nele construída embaralha fronteiras entre político e não-político.

Para o autor, a compreensão democrática do direito implica a afirmação da garantia de leis já estabelecidas, já que os direitos são a mola propulsora da democracia, não se dissociando direitos herdados e conquistados.

A democracia substitui um governo de poder legítimo por um de discussão do que é legítimo ou não, suprime um juiz mas reporta justiça à existência de um espaço público.

A degradação do espaço público implica a degradação do direito, uma vez que para ambos o debate se apresenta como fundamental, caso contrário a opinião da maioria se impõe à obediência da minoria. Por isso, a questão política, para Lefort, é a sobrevivência do alargamento do espaço público: o cerne da democracia.

\section{A RESPEITO DE OLHARES E CAMINHOS}

Na busca dos caminhos de análise alguns pressupostos nortearam este trabalho. Um deles foi olhar o desemprego como decorrência da relação entre capital e trabalho resultando em desigualdade. Outro olhar procurava a interferência de determinantes da exclusão social, tais como gênero, etnia ou idade. Para tanto, procurei dados empíricos que pudessem revelar estratégias de solidariedade privada com alguma chance de encontrar elementos que revelassem a "consciência" do direito a ter direitos.
Além dos dados empíricos obtidos em pesquisas realizadas por institutos especializados, realizei uma entrevista em profundidade com apenas um informante que pudesse revelar suas estratégias de sobrevivência, idéias e valores acerca de sua situação de desempregado, bem como suas formas de participação política.

Esta opção não significa que, no presente trabalho, se esgote a discussão sobre a possibilidade de o desemprego ser instituído politicamente na dinâmica dos direitos. Na realidade, aponta apenas para algumas articulações entre teoria e empiria, bem como para a necessidade de pesquisas que possam aprofundar tais articulações.

\section{DESEMPREGO NO BRASIL E A NOVA ORDEM MUNDIAL}

Quando levantamos a questão do desemprego temos por base algumas evidências históricas que nos levam a tematizar a exclusão e a desigualdade. Nem a transição do regime escravista para assalariado no século XIX, tampouco as depressões dos anos 30 , ou até mesmo as recessões do início das décadas de 80 e 90 foram capazes de gerar um índice tão significativo de desemprego como agora, no final desta década.

Em seu início, estavam em risco de desemprego os trabalhadores de baixa qualificação profissional. No entanto, a crise atual vem atingindo indiscriminadamente qualquer trabalhador ativo, mesmo aquele com formação universitária, jovem ou adulto.

Políticas artificiais, que se pretendem perpetuar, mostram o trabalho como algo imperecível, mitificando-o, apresentando o emprego como o seu efeito deformado. As sociedades ocidentais estão vivendo uma nova ordem - e não percebem que a vivem - na realidade de um mito da dinâmica ausente, entendido como uma ordem ainda baseada no trabalho e não na ausência dele. (FORRESTER, 1997)

O contratualismo é a metáfora fundadora da política social contemporânea, pois visa criar paradigmas sócio-políticos para enfrentar grandes turbulências econômicas à medida que permite a predominância estrutural dos processos de inclusão e exclusão. Dentre estas formas de contratualismo, segundo SANTOS (1995), podemos encontrar o pós-contratualismo e o pré-contratualismo.

O primeiro considera os indivíduos que até agora estão incluídos no contrato social (trabalhadores com contrato por tempo indeterminado), porém confiscando-lhes os direitos e a cidadania - antes inalienáveis - e passando os indivíduos de cidadãos a servos. No segundo, o précontratualismo (jovens em busca do primeiro emprego), há o pleno bloqueio de acesso à cidadania.

Suprimir o trabalho é a lógica da nova ordem mundial. O desemprego passa a ser, nesta discussão política, alvo de promessas de vagas no mercado, encobrindo a necessidade de milhões de desempregados que, na realidade, são os excluídos do grupo de assalariados sem previsão de volta. (FORRESTER, 1997) 
SANTOS (1998) trata dos problemas de exclusão como novos facismos sociais, não como um regresso aos anos 30 e 40 , visto que desta vez não se trata de um regime político mas, sim, social e civilizacional, que, ao invés de sacrificar a democracia para a manutenção do capitalismo, promove-a, não sendo necessário sacrificá-la para promover o capitalismo.

As transformações recentes do capitalismo mundial alteram substancialmente as condiçōes nacionais de produção, divisão do trabalho, ocasionando uma queda vertiginosa na quantidade de trabalho humano para a produção de mercadorias. Estas condições tornam-se cada vez mais transnacionais e mundializadas. Dessa forma, instaura-se a nova ordem, geradora dos processos de exclusão e do aumento estrutural do desemprego.

Entre 1993 e 1998 houve, no Brasil, a redução de 338,4 mil vagas de empregos formais; de julho de 1994 até os dias atuais o déficit no emprego aumentou para 764,1 mil postos de trabalho, ou seja, são 725,8 mil postos de trabalho a menos em termos de emprego formal brasileiro. Nas condições atuais há uma clara tendência de ruptura no padrão de crescimento econômico em relação ao desemprego. (POCHMANN, 1998, p.1)

Tais dados são do Instituto Brasileiro de Geografia e Estatística (IBGE), que segue recomendações da Organização Internacional do Trabalho, separando da pesquisa aqueles que trabalham e os que estão inativos, não considerando o "trabalho", mas a "ocupação".

Na PME (Pesquisa Mensal de Emprego-IBGE) são consultados 38.500 domicílios em diversas regiões metropolitanas do Brasil, entre as quais Recife, Salvador, Belo Horizonte, Rio de Janeiro, São Paulo e Porto Alegre, considerando a população em idade economicamente ativa, i.é., a partir de 15 anos. (IBGE, 1998)

Pela metodologia do IBGE, uma pessoa empregada é aquela que trabalha para um empregador e recebe remuneração em dinheiro, ou em qualquer outra forma de pagamento (moradia, alimentação, vestuário, etc.), incluindo pessoas em serviço militar obrigatório e clérigos. A população considerada desocupada é aquela que não tinha trabalho, ou nunca trabalhara, mas procurara emprego efetivamente em jornais e agências. A população ocupada é aquela que tem alguma ocupação - com carteira assinada ou não — durante o período de pesquisa.

Sendo assim, o IBGE considera a taxa de desemprego aberto, a relação do número de pessoas desocupadas (procurando trabalho) e pessoas que estão em idade economicamente ativa. A taxa de "desemprego aberto" para pessoas que nunca trabalharam (jovens à procura do primeiro emprego) é a relação entre pessoas que nunca trabalharam - consideradas desocupadas - e o número de pessoas em idade economicamente ativa. Com esta metodologia, o IBGE lançou, no mês de junho de 1998, a média de população desocupada, ou taxa de "desemprego aberto": 7,97\% a 8,71\%.

A partir do exposto podemos estabelecer uma comparação entre os dados coletados pelo IBGE e os coletados por outra instituição, o Departamento Inter-Sindical de Estudos Sociais e Econômicos (DIEESE). Tal comparação revela diferentes procedimentos metodológicos.
No tocante à metodologia, ao adotar o conceito de desemprego aberto, que considera ocupação remunerada até uma semana anterior à pesquisa, o IBGE negligencia a precariedade do mercado de trabalho, considerando ocupado aquele que se encontra em situação instável de emprego informal, ou os vulgarmente chamados "bicos".

Este é um dos grandes problemas da metodologia do IBGE. Substitui o número de desempregados, pois considera empregados aqueles que têm ocupações temporárias, trata essa situação como um mero problema quantitativo e obscurece a ausência dos direitos e o nível de miserabilidade em que estas pessoas se encontram.

A ênfase na crise de desemprego e precariedade do mercado de trabalho é dada pela análise do DIEESE. Nela, o conceito de desemprego é mais abrangente e capta situações mais complexas, como os problemas decorrentes de políticas públicas insuficientes na geração de empregos, o que também significa considerar que a pessoa que se encontra desempregada e procura por um emprego tem necessidade de sobreviver. "Bicos", para o DIEESE, não significam empregos.

Segundo o IBGE, se uma pessoa presta algum serviço com remuneração e leva mais de uma hora semanal para realizá-lo, ela é considerada ocupada, mesmo que esteja à procura de emprego.

A taxa de desemprego em 1998, segundo o DIEESE, para as mesmas capitais pesquisadas pelo IBGE, são de máxima de 22,6\% em Salvador, no mês de fevereiro, e mínima de $13,7 \%$ em Porto Alegre, no mesmo mês. Somente na grande São Paulo a taxa de desemprego cresceu, de $8,7 \%$ em 1989 para $18,1 \%$ em 1998. (PRADO, 1998, p.22-25)

Ainda segundo o DIEESE, cerca de $13,2 \%$ das pessoas entrevistadas estão há mais de dois anos desempregadas, aumentando, assim, o índice de trabalhos informais de baixa remuneração.

De acordo com o coordenador do DIEESE, Antônio Prado, o desemprego no Brasil é crescente e grave, porque dobrou desde o início da década de $90 \mathrm{e}$, atualmente, decorre de uma política de estabilização monetária que diminui o incentivo a setores produtivos internos que geram empregos.

"a década de 90 deverá ser reconhecida pela história nacional como a do maior desemprego do século 20. Como consequêencia, projeta-se um maior agravamento das condições sociais, como a violência urbana, a desagregação familiar, a instabilidade e a precariedade de renda, aprofundando a marginalização de uma parcela expressiva da população brasileira." (POCHMANN, 1998, p.1)

Considerando que o crescente desemprego, no Brasil, constitui uma questão social marcada pela desigualdade e também pela exclusão, o político pode dela emergir como afirmação de cidadania e ampliação do espaço público. 


\section{A DESEMPREGADA}

Visto que este trabalho se orienta pela investigação de formas de participação política que possibilitem a instituição do desemprego - um problema social - em questão política, resolvi realizar uma entrevista que pudesse indicar o grau de consciência da entrevistada acerca de seus direitos e de sua participação política. A escolha de uma pessoa com curso superior deve-se ao fato de poder encontrar, em seu depoimento, uma visão de mundo capaz de abordar o desemprego como um fenômeno coletivo, já que esta perspectiva era fundamental para minhas reflexões teóricas.

A pessoa escolhida tem formação universitária, é professora de Filosofia, solteira, com 48 anos e tem uma filha. Seu último emprego foi na Universidade Estadual de Londrina, como professora celetista com contrato temporário; atualmente encontra-se desempregada. Anteriormente, já trabalhou em programação visual de livros e revistas, em jornal diário, foi secretária, recepcionista e tradutora.

Para a entrevistada existe uma distinção entre $\mathrm{em}$ prego e trabalho. Considera que o Estado cria emprego, enquanto o que realmente conta é o trabalho, ou seja, valoriza a produção para o crescimento econômico do país.

"porque eu acho o seguinte, as pessoas pensam muito no emprego, e emprego significa salário no fim do mês, e não é só isso, porque o trabalho constrói benefícios, o trabalho constrói bens, o país se constrói através de trabalho e não de emprego, vamos parar de falar em emprego! (...) emprego o Estado dá".

Para a entrevistada a crise que estamos vivendo é do Brasil e, não, propriamente mundial, porque, para ela, a crise é mais uma vez dos países do Terceiro Mundo. Entende que existe um grande problema de valores no momento em que superestimamos a importação de tudo que se utiliza, até mesmo dentro de casa, como se tais produtos fossem necessários e, no entanto, são "necessidades criadas".

Ela exemplifica esta "necessidade criada" pela transferência das montadoras de automóveis que se instalaram no Paraná. Para ela, a nossa necessidade é industrializar o que se produz no próprio estado. Considerando o Paraná um estado agrícola, afirma que a necessidade que temos é a agroindústria, ou seja, que a política de criação de empregos é inadequada, considerando que a crise não é mundial e, sim, do Terceiro Mundo, pois, segundo ela, a economia globalizada prioriza a importação e não a produção para os países não-hegemônicos.

Segundo seu entendimento, as reformas da educação que estão sendo propostas pelo governo brasileiro são para criar condições de capacitação e qualificação profissionais. Tanto a qualificação quanto a capacitação, às quais se refere, não fazem sentido, uma vez que avalia que o mercado não está oferecendo vagas de emprego. Ressalta que a sua própria situação aponta para este problema, pois é formada em Filosofia e precisa do mestrado para dar aulas em uma universidade, porém, lembra que as vagas dos programas de pós-graduação são poucas. Outro problema destacado por ela é que a Filosofia no segundo grau ainda não está totalmente implantada, sendo assim teria que procurar outras opções fora de sua qualificação.

Mas quais são as opções? Segundo a entrevistada, antigamente havia um campo alternativo, como vender um sanduíche, ou ser um free lancer de alguma empresa, por exemplo. Nesse último caso, trata-se de um trabalho temporário que, hoje, chamamos de terceirização. Mas este tipo de trabalho foi institucionalizado e, para ela, estas opções deixaram de existir no mercado.

Atualmente não vê mais esse campo alternativo e diz que a capacitação acaba até dificultando quando alguém como ela, que tem formação universitária, procura um emprego que não exija qualificação.

"as pessoas têm medo de te contratar, porque têm absoluta certeza de que o lugar dela está correndo risco (...) para abrir mercado de trabalho com a desculpa de que a gente tem que se capacitar, e o pobre coitado que não conseguiu fazer secundário porque não teve condições, ele tá fora do mercado de trabalho, o que também não é verdade, porque a quantidade de universitários que tá fora, este é mais um funil que está se fazendo, justamente porque você tem a grande parte de gente formada fora do mercado de trabalho hoje, então isso tudo da conjuntura que está explicando o que acontece comigo, eu não posso dar aula em uma universidade porque não tenho mestrado, e não posso fazer mestrado porque não tem vaga".

Tendo em vista estes problemas para conseguir emprego, a entrevistada fala sobre algumas possibilidades e estratégias de sobrevivência. Ela diz que na parte de programação visual de livros, revistas e jornais ela virou "peça de museu", devido ao uso do computador, afirmando que nesse meio ela é mais uma desempregada.

Outro campo no qual poderia investir é o das artes, pois ela desenha, pinta e já fez vária exposições. Contudo, diz que é muito difícil ser artista no Brasil, "os campos são fechados e também não tem uma discussão sobre arte".

Ela também tem doze anos de estudos de Astrologia e como astróloga tem dificuldades para sobreviver. Em primeiro lugar, diz ela, devido ao preconceito, as pessoas não conhecem e muitas se recusam a conhecer. Em segundo, afirma que em situações de crise estas coisas, neste caso a astrologia, são deixadas para segundo plano e até mesmo excluídas de suas vidas.

"digamos que eu sou uma pessoa que poderia achar vários buracos pra trabalhar só que os buracos estão meio entupidos de gente, isso é uma realidade (...) vamos ter que buscar saídas individuais pra não morrer de fome, tem hora que os amigos vão ter que socorrer, ainda bem que tem alguns amigos empregados que podem te socorrer em alguns momentos em que a coisa fica muito difícil, e não tem opção".

Mas, ainda assim, ela acredita que é justamente em tempos de crise que as pessoas devem agir de maneira mais 
coletiva. Ressalta que é preciso mudar a mentalidade individualista do "salve-se quem puder" e começar a enxergar as coisas como coletivas e lutar juntos pelos direitos:

"penso que tem um grau de dignidade de exploração que não dá pra aceitar não, a partir dali é porrada mesmo é briga braçal se for o caso (...) as pessoas enfrentam as suas situações individuais e não vêem saída e continuam enxergando sua situação de desemprego como individual, quando ela e o bairro inteiro estão desempregados, aquilo que não acontece só comigo não é mais problema meu, é nosso, e o que nós lutamos juntos? Nada, pelo contrário, as pessoas ficam disputando a mesma vaga e baixam ao nível mais baixo da degradação que é aceitar ser explorado pra tirar a vaga do outro, isso é indigno".

Quando abordamos os temas direitos e cidadania, fez uma crítica à Carta dos Direitos do Homem, dizendo que a definição de homem que consta na Carta não possui humanidade nenhuma, e salienta que este é um dos motivos pelo qual estamos vivendo esta realidade, já que não atingimos "humanidade".

"a gente começa a pensar, o que eu acredito que se esquece é justamente da pessoa, como cidadão no caso, (...) eu penso que tá muito claro aqui no Brasil de que nós vivemos essa realidade porque nós não atingimos a humanidade, nós não temos nenhum dos direitos humanos da carta dos direitos humanos e se aquilo é definição de homem, não tô dizendo que aprovo ou desaprovo aquilo, são meus questionamentos, mas se aquilo é definição de ser humano, nós não somos (...) porque nós não somos seres humanos porque nós não reivindicamos também a nossa humanidade".

A entrevistada nunca se filiou a partidos políticos ou qualquer tipo de associação, mas afirma que a atuação política sempre fez parte de sua vida. No período da ditadura no Brasil, trabalhava em um jornal alternativo, o que ela considera uma atitude política adequada, principalmente quando se leva em conta o período em que atuou no jornal.

Para ela não há como instituir politicamente o desemprego, porque o desemprego faz parte da luta por interesses, ou melhor, atende ao efeito de interesses do poder instituído.

Fica clara em seu discurso a diferença que faz entre "atuação política " e "politicagem". Esta última, segundo ela, pode ser encontrada em qualquer lugar, mas afirma que atuação política está relacionada à educação com vistas na participação em movimentos populares. Vejamos com suas próprias palavras:

"se é de manifestação eu sempre tive nelas, quando eu acredito que vale a pena. Se for atuação, participação enquanto atuação política, penso que eu nunca consegui não fazer (...) dentro dos limites, não nesta politicagem, essa coisa que a gente vê em todos os lugares, mas atuação política mesmo, mais de educação, de ensino, de participação de movimentos mais populares."

A entrevistada faz distinção também entre "manifestações populares" e "setoriais". Por sua história de participação em movimentos políticos - período da ditadura no Brasil - , podemos perceber que sua proposta política está mais relacionada à idéia de revolução ou de grandes transformações a partir de movimentos sociais que questionem toda a estrutura social.

"aqui no Brasil quando eu cheguei não tiveram, ou poucas manifestações, a do Collor que eu acredito que todos nós participamos também e acho que foi só, porque não me lembro de nenhuma outra manifestação social a não ser setoriais, dos bancários, manifestações disto ou daquilo, não me parece que nos últimos anos tiveram manifestações populares fora de setores".

Nesse caso, em minha pesquisa, são importantes também as manifestações setoriais por melhores condições de saúde, educação e moradia, entre outras. Elas ampliam os espaços políticos, uma vez que diferentes interesses podem ser rivalizados e ampliados a partir do espaço privado, para o público restrito, até chegar-se ao espaço público mais amplo.

Isto nos lembra LEFORT (1991) quando se refere ao duplo movimento do político no social: a "ocultação" e "aparição". O político está oculto quando percorre as esferas institucionais e sua aparição se dá quando a sociedade se manifesta e amplia o espaço público. Para Lefort, espaço democrático é o território das incertezas, e o grande paradoxo da democracia está justamente em relacionar soberania popular apenas ao número de manifestantes.

\section{IMPORTÂNCIA DA AÇÃO COLETI- VA: REVOLUÇÃO X AMPLIAÇÃO DE CIDADANIA}

A discussão teórica desenvolvida pretendeu destacar uma nova forma de participação política relacionada às transformações na divisão social do trabalho, no processo produtivo e na reprodução de capital.

A ordem econômica atual revela um perfil de trabalhadores sem trabalho e sem o antigo papel do trabalho na sua integração ao mundo público. É por esta razão que não há como situar o indivíduo na sociedade apenas através de sua condição de trabalhador, visto que, na nova ordem econômica, sua identidade tende a se deslocar mais para formas privadas de relações que propriamente se revelar no mundo público.

É justamente pelo fato de o trabalhador se encontrar fora do mundo da produção que trabalhamos com o pressuposto de que questões sociais tendem a se deslocar para as redes de sociabilidade primárias. 
Considerando que o espaço público é o lugar da política, a exemplo de LEFORT (1991), entendemos que formas de manifestação em busca da cidadania podem ser procuradas nos lugares nos quais elas não aparecem. Nesse caso, o político se oculta nas redes privadas, e é preciso investigar se há possibilidade de instituir politicamente o social.

Se levarmos em conta a fala da entrevistada é possível notar que, para ela, a mudança da mentalidade da população brasileira é importante, já que esta acredita que o desemprego é um problema individual e que, em geral, o brasileiro se culpa individualmente pela sua situação de desemprego, não percebendo que se trata de um problema coletivo.

A fala da entrevistada revela um tipo de consciência marcado pelo tempo pretérito de sua militância. Acredita que a educação política pode mudar a mentalidade individualista e que, a partir de então, será possível a luta coletiva pelos direitos, a exemplo do que ressalta DAGNINO (1994).

No entanto, seu entendimento do que vem a ser participação política está mais relacionado à idéia de revolução do que propriamente de busca de cidadania e conquista de direitos.

O presente trabalho se propôs avaliar se os direitos herdados ou direitos garantidos pelo Estado podem motivar os indivíduos para a busca de novos direitos, como sugere Hannah Arendt: o direito a ter direitos.

Embora a entrevistada entenda que somente através de ações coletivas se possa resolver o problema do desemprego, considera que estas são manifestações setoriais, corporativas. De modo semelhante aos desempregados com menor grau de escolaridade e com menor qualificação, admite que busca suas formas de sobrevivência no espaço privado. Nos momentos de maior dificuldade, reflui às suas redes de sociabilidade primária, ou seja, suas estratégias de sobrevivência tendem a se deslocar mais para o espaço privado do que, propriamente, para o espaço público.

Desse modo, podemos entender este refluxo a partir da noção de "cidadão privado" (KOWARICK, 1997), i.é., quando a solidariedade do mundo privado suprime as questões sociais do mundo público.

\section{REFERÊNCIAS BIBLIOGRÁFICAS}

ANTUNES, Ricardo. "As metamorfoses e a centralidade do mundo do trabalho". Revista da ADUEL-SINDIPROL, ano 1, n.1, p.8-14, 1996.

ARENDT, Hannah. Entre o passado e o futuro. São Paulo: Perspectiva, 1992.

CASTEL, Robert. As metamorfoses da questão social: uma crônica do salário. Petrópolis: Vozes, 1998.

DAGNINO, Evelina. "Os movimentos sociais e a emergência de uma nova noção de cidadania”. In: Os anos 90: política e sociedade no Brasil. São Paulo: Brasiliense, 1994. p.103-115.

FALCON, Francisco \& MOURA, Gerson. A formação do mundo contemporâneo. Rio de Janeiro: Campos, 1989. [on line] Disponível na internet via http//www.nethistoria.com/docs/docs06.shtml, arquivo capturado em 15 de janeiro de 1999.

FORRESTER, Viviane. O horror econômico. São Paulo: Ed. UNESP, 1997.

IBGE-INSTITUTO BRASILEIRO DE GEOGRAFIA E ESTATÍSTICA
Pesquisa Mensal de Emprego: estatísticas do mês de junho de 1998. [on line] Disponível na internet via http//www.ibge.gov.br/informações/índice/pme0698.htm, arquivo capturado em 19 de dezembro de 1999.

KOWARICK, Lúcio. Pobreza \& moradia \& idosos \& violência urbana: a exclusão social na região metropolitana de São Paulo. São Paulo, 1997. (Projeto de Pesquisa) - Universidade de São Paulo.

LANG, Alice da Silva Gordo. "Considerações sobre os conceitos de estratificação social e de posição no sistema de relações sociais de produção: sua operacionalização em uma pesquisa empírica". Ciência e cultura, v.34, n.1, p.13-21,1982.

LEFORT, Claude. A invenção democrática. São Paulo: Brasiliense, 1987. Pensando o político: ensaios sobre democracia, revolução e liberdade. Rio de Janeiro: Paz e Terra, 1991.

OFFE, C. Capitalismo desorganizado. Rio de Janeiro: Tempo Brasileiro, 1989.

POCHMANN, Márcio. "Brasil perde capacidade de empregar". Folha de S.Paulo, 23 abr.1998, cad. 2, p.1.

PRADO, Antônio. "O rosto do desemprego". Teoria \& Debate, ano 11, n.38, p.22-25, 1998.

SANTOS, Boaventura de S. "A construção multicultural da igualdade e da diferença". (Palestra proferida no VII Congresso Brasileiro de Sociologia, realizado na UFRJ de 4 a 6 de setembro de 1995). p.1-3

"Os facismos sociais". Folha de S.Paulo. Folha Mundo, 6 set.1998, 